\title{
Clinical Comparative Study for Some Biochemical Changes in Sera of Pregnant with Iron Deficiency Anemia
}

\author{
Ahmed Ghitheeth Mathwar', Raid M.H. Al-Salih' \\ ${ }^{1}$ Post Graduate, ${ }^{2}$ Prof., Chemistry Department, College of Science, Thi-Qar University, Iraq
}

\begin{abstract}
The aim of this study was to study the evaluation of serum oxidation in pregnant women with iron deficiency anemia by measuring lipid oxidation (MDA), and antioxidant status by analogy (Ferritin).Also, Examination of erythropoietin (EPO) levels in pregnancy with iron deficiency anemia. Blood samples were obtained from (80) pregnant women with anemia divided according to the stage of pregnancy and iron deficiency as follows: 20 patients in the second third with anemia without iron deficiency, 20 patients in the second third with anemia with iron deficiency, 20 patients In the third trimester with anemia without iron deficiency, 20 patients in the third trimester have anemia with iron deficiency. In addition to (40) healthy pregnant women as a control group. Divided into two groups, 20 patients in the second trimester and 20 patients in the third trimester.

Results: The results show a presence of a significant increase in MDA and EPO in all groups of patients in Iron deficiency in comparison with control group. But, Ferritin levels showed a significant decrease in all groups of patients in Iron deficiency and Iron normal comparison with control group.
\end{abstract}

Keyword: Erythropoietin, Malondialdehyde, Ferritin, Pregnancy, Iron deficiency anemia

\section{Introduction}

Anemia is one of the most important health problems in the world. Iron deficiency anemia is the most common form of nutritional deficiency that affects both developing and developed countries. An assessment by WHO directly or indirectly attributes approximately 591,000 perinatal deaths and 115,000 maternal deaths worldwide to iron deficiency anemia ${ }^{(1)}$. The South Asian countries have the highest incidence of anemia in the world. Around half of the world's maternal deaths from anemia occur in South Asian countries, and India accounts for around 80 per cent of the deaths ${ }^{(2)}$. Anemia affects all age ranges from childhood to adolescence to perimenopausal age. The factors for the high incidence of anemia include low

\footnotetext{
Corresponding Author:

Raid M.H. Al-Salih

Prof., Chemistry Department, College of Science, Thi-

Qar University, Iraq

e-mail: raidstry@gmail.com
}

iron dietary consumption, reduced iron bioavailability, phytate-rich diet, bad eating habits, frequent menstrual blood loss and increasing proportion of infections such as malaria and roundworm infestations ${ }^{(3)}$. Due to increased demand from the increasing fetus, the condition gets exacerbated during pregnancy. Throughout pregnancy it is recommended that prophylactic oral iron meet the increased requirement during the antenatal phase. Compliance due to associated gastrointestinal side effects such as bloating, diarrhea, heartburn, nausea, constipation and dark stools is the main issue with oral iron therapy. So, too.Oral therapy does not suffice to treat moderate to serious anemia, especially in the late second and third trimesters. Parenteral therapy provides a stronger response in these patients and can reduce the need for antenatal and postpartum blood transfusions ${ }^{(4)}$. After iron supplementation, iron deficiency anemia occurs in several pregnant women as their iron stores need to support their own increased blood volume, as well as being a source of hemoglobin for the developing baby and for placental production ${ }^{(5)}$. The intravascular hemolysis and hemoglobinuria are other less common 
causes, pregnancy during Iron deficiency seems to cause long-term and permanent cognitive problems in the baby ${ }^{(6)}$. Erythropoietin, also known as EPO, is a glycoprotein hormone that controls the manufacturing of erythropoiesis, or red blood cells. It is a cytokine (protein signaling molecule) catalyst in the bone marrow for erythrocytes (red blood cells) $)^{(6)}$. The molecular weight of Human EPO is $34 \mathrm{kDa}$. Also known as haematopoietin or haemopoietin, interstitial fibroblasts in the kidney are produced in close association with the capillary peritubular and proximal convoluted tubules. It is also formed in the liver, in perisinusoidal cells. While liver production predominates in both the fetal and perinatal periods, during adulthood renal production predominates. Other known biological functions include erythropoietin, in addition to erythropoiesis. This plays a major role in the brain's reaction to neuronal damage, for example. The EPO also participates in the wound cure process $^{(7)}$. The erythropoietin synthesis does not have a humoral or neural regulation. The development of erythropoietin is only dependent on the content of oxygen and is regulated by the feedback principle ${ }^{(8)}$.

Malondialdehyde (MDA) is one of the end products of peroxidation of polyunsaturated fatty acids in cells. An rise in free radicals causes MDA to become overproduced. Malondialdehyde is commonly referred to as a marker of oxidant stress $\mathrm{s}$ in patients ${ }^{(9)}$.

Ferritin, a large iron storage protein, is essential to homeostasis of iron and participates in a wide variety of physiological and pathological processes. Ferritin is primarily used in clinical medicine as a serum measure of total body iron reserves. Serum ferritin plays a key role in both treatment and management in cases of iron deficiency and excess ${ }^{(10)}$.

Design of study: This study conducted at Women and Children Hospital in Al-Muthanna, Iraq, biochemistry laboratory at the period between $1 / 11 / 2019$ and $1 / 4 / 2020$. The study include (120) subjects, (80) patients with anemia (40 females second trimester divided to 20 anemia with Iron deficiency and 20 anemia non Iron deficiency, 40 femalsetherid trimester divided to 20 anemia with Iron deficiency and 20 anemia non Iron deficiency) with age range (18-40) years . While the control group, consists of (40) Healthy pregnant women divided to (20 females second trimester and 20 females therid trimester).
Table (1) Data of patients (Pregnant women with anemia) controls (Healthy pregnant women) groups.

\begin{tabular}{|l|l|}
\hline Groups & N \\
\hline Patients & 80 \\
\hline Controls & 40 \\
\hline
\end{tabular}

Collection of blood samples: Blood samples are collected. About $(5 \mathrm{~mL})$ of blood samples of Pregnant women with anemia and controls are taken and allowed to clot at room temperature in empty disposable tubes and centrifuged to separate it at 3000 rotor per minute (rpm) for $10 \mathrm{~min}$, the serum samples are separated and stored at $\left(-20^{\circ} \mathrm{C}\right)$ for later measurement of biochemical parameters, unless used immediately.

Statistical Analysis: The statistical analysis used in this study is done using Microsoft Excel 2010, the results are expressed as mean \pm standard deviations (mean \pm $\mathrm{SD})$ with LSD test. One way ANOVA-test is used to compare parameters in different studied groups. P-values $(\mathrm{P} \leq 0.05)$ are considered statistically significant .

\section{Result and Discussion}

Serume Erythropoitien concentration: Table (2) show a significant increase in concentrations of serum EPO in patients pregnancy with anemia group in comparison with control group $(\mathrm{P} \leq 0.05)$. It was also found that there was a significant increase in $3^{\text {rd }}$ groups compared to group $2^{\text {nd }}$ groups, in addition to a significant increase was observed in $3^{\text {rd }} \mathrm{D}$ group compared to $3^{\text {rd }} \mathrm{N}$, and there was also a significant increase in $2^{\text {nd }} \mathrm{D}$ group compared to $2^{\text {nd }} \mathrm{N}$ group these result agree with. Indeed, pregnancy anemia leads to increased secretion of the EPO as a response to low concentration of haemoglobin and ferritin deficiency ${ }^{(11)}$. The primary function of erythropoietin is an important hormone for the manufacture of red blood cells. No definitive erythropoiesis happens without it. Under hypoxic conditions, the kidney develops and secretes erythropoietin to improve red blood cell output ${ }^{(12)}$. Due to the physiological increase in blood volume, the increase in EPO levels is greater in the third trimester of pregnancy than in the second trimester of pregnancy. Increased renal blood flow and glomerular filtration by $30-50$ percent, and since erythropoietin is of renal origin and increased oxygenation, the concentration of the EPO has been shown to increase 2-4 times ${ }^{(8)}$. 
Table groups (2) serum EPO levels of control and 3d iron $\mathrm{D}, \mathrm{N}$ and $2 \mathrm{~d}$ iron $\mathrm{D}, \mathrm{N}$ levels.

\begin{tabular}{|c|l|c|}
\hline Groups & N & EPO $(\mathbf{m l U} / \mathbf{m l})$ Mean \pm SD \\
\hline \multicolumn{3}{|c|}{ Second Trimester } \\
\hline $2^{\text {nd }}$ Control & 20 & $84.67 \pm 14.21^{\mathrm{d}}$ \\
\hline $2^{\text {nd }} \mathrm{N}$ & 20 & $121.82 \pm 34.66^{\mathrm{c}}$ \\
\hline $2^{\text {nd }} \mathrm{D}$ & 20 & $173.38 \pm 52.98^{\mathrm{b}}$ \\
\hline \multicolumn{3}{|c|}{ Third Trimester } \\
\hline $3^{\text {rd }}$ Control & 20 & $92.84 \pm 20.98^{\mathrm{d}}$ \\
\hline $3^{\text {rd }} \mathrm{N}$ & 20 & $135.76 \pm 41.45^{\mathrm{c}}$ \\
\hline $3^{\text {rd }} D$ & 20 & $217.70 \pm 72.82^{\mathrm{a}}$ \\
\hline L.S.D & \multicolumn{2}{c}{24.19} \\
\hline
\end{tabular}

$\mathrm{N}$ : Number of subjects.

SD: Standard deviation.

LSD: Least Significant Difference.

$2^{\text {nd }}$ Control: Second Trimester Control.

$2^{\text {nd }} \mathrm{N}$ : Second Trimester Iron Normal.

$2^{\text {nd }} \mathrm{D}$ : Second Trimester Iron Deficiency.

$3^{\text {rd }}$ Control: Third Trimester Control.

$3^{\text {rd }} \mathrm{N}$ : Third Trimester Iron Normal.

$3^{\text {rd }} \mathrm{D}$ : Third Trimester Iron Deficiency.

Serum Malondialdehyde Concentration: Table (3) show a significant increase in concentrations of serum MDA in patients pregnancy with anemia group in comparison with control group $(\mathrm{P} \leq 0.05)$. It was also found that there was a significant increase in $3 \mathrm{~d}$ iron groups compared to group $2^{\text {nd }}$ groups, in addition to a significant increase was observed in $3^{\text {rd }} \mathrm{D}$ group compared to $3^{\text {rd }} \mathrm{N}$, and there was also a significant increase in $2^{\text {nd }} \mathrm{D}$ group compared to $2^{\text {nd }} \mathrm{N}$ these result agree with. Anemia is known to promote oxidative stress due to insufficient supply of tissue oxygen resulting in increased free radical development and very low levels of circulating red blood cells and mobile free radical scavengers that protect tissues from ROS-mediated harm $^{(13)}$. The increase in serum and erythrocyte fatty oxidation in pregnant women Particularly during the third trimester of pregnancy, the production of pregnancyrelated oxidative therapy is obvious in pregnant women. Thus pregnancy is a physiological condition characterized by an oxidative disorder which contributes to the initiation and progression of complications related to pregnancy ${ }^{(14)}$. The body's iron deficiency limits heme synthesis and reduces the production of red blood cells in the marrow that leads to anemia. Because energy Cellular metabolism is oxygen dependent, anemia has a wide range of clinical consequences. Anemia results in increased oxidative stress and increased peroxide in lipids. Can not exclude iron deficiency as an person with a normal body iron will coagulate a large portion of body iron before hemoglobin levels decrease The enzymes used in the cycle of oxidative metabolism need iron to be less than the laboratory meaning of anemia. At the same moment, This should be taken into account that iron iron is used to treat iron by mouth during pregnancy as a drug Strong oxidation and several studies have shown that iron-deficient people are more prone to this treatment than iron therapy-induced oxidative stresses. The concentration of malaundaldehyde (MDA) in pregnant women with iron deficiency anaemia is higher in this study ${ }^{(15)}$.

\section{Table groups (3) serum MDA levels of control and} 3d iron $D, N$ and $2 d$ iron $D, N$ levels.

\begin{tabular}{|c|l|c|}
\hline Groups & N & MDA(umol/L) Mean \pm SD \\
\hline \multicolumn{3}{|c|}{ Second Trimester } \\
\hline $2^{\text {nd }}$ Control & 20 & $2.23 \pm 0.59^{\mathrm{d}}$ \\
\hline $2^{\text {nd }} \mathrm{N}$ & 20 & $2.48 \pm 0.57^{\mathrm{d}}$ \\
\hline $2^{\text {nd }} \mathrm{D}$ & 20 & $3.12 \pm 0.95^{\mathrm{c}}$ \\
\hline \multicolumn{3}{|c|}{ Third Trimester } \\
\hline $3^{\text {rd }}$ Control & 20 & $2.56 \pm 0.43^{\mathrm{d}}$ \\
\hline $3^{\text {rd }} \mathrm{N}$ & 20 & $4.01 \pm 0.94^{\mathrm{b}}$ \\
\hline $3^{\text {rd }} \mathrm{D}$ & 20 & $5.10 \pm 1.45^{\mathrm{a}}$ \\
\hline L.S.D & & 0.45 \\
\hline
\end{tabular}

Serum Ferritin concentrations: Table (4) show a significant decrease in concentrations of serum ferritin in patients pregnancy with anemia group in comparison with control group $(\mathrm{P} \leq 0.05)$. It was also found that there was a significant increase in $3^{\text {rd }}$ groups compared to group $2^{\text {nd }}$ groups, in addition to a significant decrease was observed in $3^{\text {rd }} \mathrm{D}$ group compared to $3^{\text {rd }} \mathrm{N}$, and there was also a significant decrease in $2^{\text {nd }} \mathrm{D}$ group compared to $2^{\text {nd }} \mathrm{N}$ groupthese result agree with.Although concentrations of haemoglobin and ferritin are both iron deficiency markers, haemoglobin is a late marker, and may not reflect the status of tissue iron. In general, however, serum ferritin (SR) is considered the best measure of iron deficiency during pregnancy. The level falls early of iron deficiency and is not impaired by the recent ingestion of iron ${ }^{(16)}$.A study of 100 women in the second and third trimester of pregnancy and anemia was shown as follows, iron deficiency anemia $(\mathrm{Hb} \leq 10.5 \mathrm{~g} /$ $\mathrm{dl}$; ferritin $\leq 12 \mathrm{ng} / \mathrm{ml}$ ). Anemia not due to iron deficiency $(\mathrm{Hb} \leq 10.5 \mathrm{~g} / \mathrm{dl} \text {; ferritin> } 12 \mathrm{ng} / \mathrm{ml})^{(17)}$. 
Table groups (4) serum Ferritin levels of control and $3 d$ iron $\mathrm{D}, \mathrm{N}$ and $2 \mathrm{~d}$ Iron $\mathrm{D}, \mathrm{N}$ levels.

\begin{tabular}{|c|l|c|}
\hline Groups & No & SR(ng/ml) Mean \pm SD \\
\hline \multicolumn{3}{|c|}{ Second Trimester } \\
\hline $2^{\text {nd }}$ Control & 20 & $25.36 \pm 7.97^{\mathrm{a}}$ \\
\hline $2^{\text {nd }} \mathrm{N}$ & 20 & $16.61 \pm 4.84^{\mathrm{b}}$ \\
\hline $2^{\text {nd }} \mathrm{D}$ & 20 & $7.96 \pm 2.33^{\mathrm{c}}$ \\
\hline \multicolumn{3}{|c|}{ Third Trimester } \\
\hline $3^{\text {rd }}$ Control & 20 & $25.66 \pm 6.60^{\mathrm{a}}$ \\
\hline $3^{\text {rd }} \mathrm{N}$ & 20 & $18.59 \pm 6.33^{\mathrm{b}}$ \\
\hline $3^{\text {rd }} \mathrm{D}$ & 20 & $8.30 \pm 2.50^{\mathrm{c}}$ \\
\hline L.S.D & & 2.80 \\
\hline
\end{tabular}

Conclusion

1- The levels of the hormone erythropoietin are higher in women with anemia and it increases more in women with anemia with iron deficiency.

2-The levels of lipid peroxide (MDA) markers were elevated in pregnant women with iron deficiency anemia and also elevated in pregnant women with anemia without iron deficiency.

3-Fritin levels are in iron deficiency groups below of iron normal groups.

Ethical Clearance: The Research Ethical Committee at scientific research by ethical approval of both MOH and MOHSER in Iraq

Conflict of Interest: Non

Funding: Self-funding

\section{References}

1. Jose A, Mahey R, Sharma JB, et al. Comparison of ferric Carboxymaltose and iron sucrose complex for treatment of iron deficiency anemia in pregnancyrandomised controlled trial. BMC Pregnancy Childbirth. 2019;19(1):1-8.

2. Smith KR, Mehta S. Comparative risk assessments for indoor air pollution in India. J Environ Stud Policy. 2002;5(2):71.

3. SINGH P, Toteja GS. Micronutrient profile of Indian children and women: summary of available data for iron and vitamin A. Indian Pediatr. 2003;40(5):477-479.
4. Kriplani A, Mahey R, Dash BB, Kulshreshta V, Agarwal N, Bhatla N. Intravenous iron sucrose therapy for moderate to severe anaemia in pregnancy. Indian J Med Res. 2013;138(1):78.

5. Knight T, D'Sylva L, Moore B, Barish CF. Burden of iron deficiency anemia in a bariatric surgery population in the United States. J Manag care Spec Pharm. 2015;21(10):946-954.

6. Sirén A-L, Fratelli $M$, Brines $M$, et al. Erythropoietin prevents neuronal apoptosis after cerebral ischemia and metabolic stress. Proc Natl Acad Sci. 2001;98(7):4044-4049.

7. Haroon ZA, Amin K, Jiang X, Arcasoy MO. A novel role for erythropoietin during fibrininduced wound-healing response. Am J Pathol. 2003;163(3):993-1000.

8. Obeagu EI, Ezimah AC, Obeagu GU. Erythropoietin in the Anaemias of Pregnancy: A Review. Int J Curr Res Chem Pharm Sci. 2016;3(3):10-18.

9. Gaweł S, Wardas M, Niedworok E, Wardas P. Malondialdehyde (MDA) as a lipid peroxidation marker. Wiad Lek (Warsaw, Pol 1960). 2004;57(910):453.

10. Knovich MA, Storey JA, Coffman LG, Torti S V, Torti FM. Ferritin for the clinician. Blood Rev. 2009;23(3):95-104.

11. Ervasti M, Kotisaari S, Heinonen S, Punnonen K. Elevated serum erythropoietin concentration is associated with coordinated changes in red blood cell and reticulocyte indices of pregnant women at term. Scand J Clin Lab Invest. 2008;68(2):160-165.

12. Livnah O, Johnson DL, Stura EA, et al. An antagonist peptide-EPO receptor complex suggests that receptor dimerization is not sufficient for activation. Nat Struct Biol. 1998;5(11):993-1004.

13. Bhale D V, Hivre MD, Mahat RK, Bujurge AA. Study of malondialdehyde (MDA) as a marker of oxidative stress in anemic pregnant women. Int $\mathbf{J}$ Recent Trends Sci Technol. 2013;9:149-151.

14. Mutinati M, Piccinno M, Roncetti M, Campanile D, Rizzo A, Sciorsci RL. Oxidative stress during pregnancy in the sheep. Reprod Domest Anim. 2013;48(3):353-357.

15. Bhale DV, Patil DS, Mahat RK. Study of malondialdehyde (MDA) as a marker of oxidative stress in obese male individuals. Int J Recent Trends Sci Technol. 2014;10:51-52. 
16. Adediran A, Gbadegesin A, Adeyemo TA, et al. Haemoglobin and ferritin concentrations of pregnant women at term. Obstet Med. 2011;4(4):152-155.
17. Tiwari M, Kotwal J, Kotwal A, Mishra P, Dutta V, Chopra S. Correlation of haemoglobin and red cell indices with serum ferritin in Indian women in second and third trimester of pregnancy. Med $\mathbf{J}$ armed forces india. 2013;69(1):31-36. 